\title{
German leader for JET project
}

DR Hans-Otto Wüster, a West German accelerator physicist presently on the directorate of CERN, was named on 20 December as project leader for the building of JET, Europe's planned giant torus for extending fusion energy research. Dr Paul Rebut, the French physicist who has led the design team for JET, has been named deputy, and Dr Romano Toschi (currently head of the Italian fusion effort based at Frascati) will be Chairman of the Management Committee. All three appointments are provisional, but are expected to be adopted formally by the Council of Ministers early in 1978.

Dr Wüster's appointment is bound to be felt as somewhat of a rebuff to Rebut: but it was not unexpected. This is not because of any failing in Rebut, but because of the vexed European politics that have dogged JET from its inception. When the decision was made last year that JET should come to the Culham fusion laboratory in the UK (where Rebut's design team had been based) rather than to Garching in West Germany, it was felt that some kind of recompense should be paid to Germany. The appointment of Wuister to the top job achieves this-if to the chagrin of France.

Wüster is not well known at Culham-his field has been high energy physics, not fusion-and he

\section{Construction shares}

ONE of the most pressing tasks the UK research councils will have to tackle early in the new year will be to decide how to spend their individual allocations of the money promised them late last November and early December for construction and energy conservation. Firm decisions must be made very soon because the money has to be spent in 1978-79.

The Advisory Board for the Rescarch Councils (ABRC) announced its decision on how to divide the total sum between the individual research councils just hefore Christmas: a total of $£ 4.5$ million had to be shared between four research councils (the Social Science Research Council did not put in a bid) and the British Museum (Natural History). Initially, $£ 4$ million had been set aside for the recipient bodies of the science budget to spend on construction during 197879; but in December, when the Secretary of State for Energy announced the UK's $£ 320$ million energy conservation programme, the sum was increased to $£ 4.5$ million. $£ 1.1$ million of it is to may find his initial reception cool. But he has time yet to work out his relationship with Rebut and Toschi and those of the design team still left at Culham. The Interim JET Council that appointed him, composed of representatives of all the nations contributing to JET, is suffering from the usual problems of large international committees and is not making its decisions particularly rapidly. It seems unlikely that the team will be completed before July, and meanwhile the main competitor -. The Princeton Tokamak-has a chance to forge ahead. After all the earlier delays in the JET project Culham staff look on this further constraint somewhat resignedly.

Wüster himself is no stranger to large international scientific projects. $\mathrm{He}$ was deputy to John Adams during the building of the $400 \mathrm{GeV}$ SPS acelerator. Once it was agreed to build it, the SPS became a great European success-built under budget, ahead of schedule, and beyond specifications. Wüster managed the budget of the SPS, and no doubt his success there influenced the JET Council. It will be interesting to see if he can be successful with the budget and management of JET, in a technology he knows less well.

Staff at CERN respect Wüster as a man with great administrative ability, a man who has his goals very clearly

be spent on energy conservation.

The $£ 4.5$ million has been divided as follows: the Agricultural Research Council is to receive $£ 1.07$ million, of which $£ 0.27$ million is for energy conservation; the Medical Research Council, £0.73 million, of which 0.13 million is for energy conservation; the Natural Environment Research Council, $£ 0.65$ million, of which $£ 0.15$ million is for energy conservation; the Science Research Council $£ 1.75$ million; and the British Museum (Natural History) $£ 0.3$ million.

The Natural History Museum probably has the firmest plans of what to do with its share. Most of it will be used to provide accommodation for fossil collections and staff at the museum's station at South Ruislip whilst preparations for a new exhibition hall in part of the main building get underway.

As yet, however, the research councils claim to have few firm plans for spending their shares, even though they must each have put forward definite proposals to the ABRC. But they do agree that major new capital projects are out of the question:

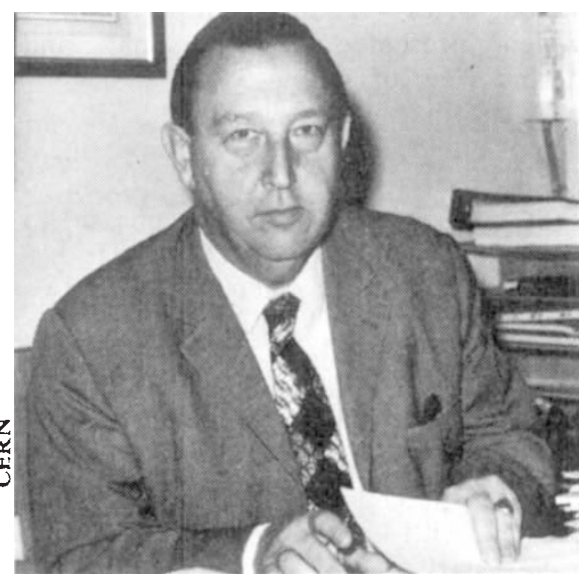

Hans-Otto Wuster: goals clearly in mind

in mind, a blustering, jovial man "who will pile in rapidly" and take to his job with enthusiasm.

Another undoubted asset Wüster will bring to JET is his long-standing friendship with his opposite number at Princeton: Dr Paul Reardon who heads the Princeton Tokamak team. Reardon was also a high energy physicist; and he played a similar role to Wüster's in the building of the Fermilab National Accelator, the $400 \mathrm{GeV}$ US competitor to Europe's SPS. Fermilab was built first, and skimmed the cream, because of the delays that hit CERN in finding a site and funding in Europe. Wüster will no doubt go all out to prove that Europe can, sometimes, be first.

Robert Walgate

the fund is too small and the time available too short. Most of the money will be spent on extending or improving existing buildings or speeding up construction work already started. For example, the SRC will use some of its share to speed up work on the nuclear structure facility at the Daresbury Laboratory and to extend some of its central user facilities. The NERC may use some of its share to put into operation existing plans to extend facilities at the Institute of Hydrology.

Judy Redfearn

\section{BBC commemorates Bronowski}

GeOrge Steiner, a controversial man of letters and champion of science, who learned physics from Enrico Fermi and chemistry from Harold Urey, will broadcast live in the UK on $\mathrm{BBC} 2$ television next Tuesday at $8.10 \mathrm{pm}$ in the first Jacob Bronowski memorial lecture. Bronowski, devoted to what he called 'the democracy of the intellect', literally gave himself to an epic tele- 
vision series-'The Ascent of Man'-which presented his personal and heroic view of science as the saviour of mankind. Bronowski died shortly after completing the programme; these lectures are the BBC's tribute to him.

Steiner is an interesting choice to lead off the memorial lectures. He has many points of contact with Bronowski; and as many differences. Both were Jewish exiles from Europe: the Nazi holocaust is writ large in both their lives, and both have shown themselves aching to find escape from it. The ultimate intellectual sanctity of science, with its references to verifiable fact, particularly in the physical sciences and mathematics, appealed deeply to both men as the antithesis of dogmatism. But whereas Bronowski searched for a release, in the fashion of The Enlightenment, for all of mankind, Steiner appears to look only towards an elite, a bright spark in the darkening eclipse of humanity.

Steiner will argue in his lecture that it is pointless to look for controls on the pursuit of science; for knowledge will out, somewhere, sometime. One day scientists will make their test-tube babies. One day there will be genetic engineering of human beings. We are powerless against the march of truth. Steiner will prove himself the hawk of science, where Bronowski was the dove. In the process he may do science a disservice. He is a great acquisitor of knowledge: 'What else is there?' he asks. Bronowski also asked for compassion, an emotion that Steiner might be suspected of dismissing as romantic.

In the 'Ascent of Man' Bronowski drew attention to a man who he said was the most intelligent he'd known: Johnny von Neumann, the originator of games theory. Von Neumann failed mankind, said Bronowski, as an intellectual elitist who believed not in the democracy but the aristocracy of the intellect. Steiner appears to fall into the same mould as von Neumann.

Steiner learned science at the University of Chicago in the late 1940s. He "scraped" a first and to his lasting regret was turned away from science by his careers advisor who said he could not cope with physics (but that was Chicago in the days of Fermi; Lee and Yang were students) and that the rest of science was "bottle-washing". Steiner, fluent in four languages, turned to journalism and ultimately to the study of language.

He would have liked to have been a biologist. His passion is mathematics and his heroes are mathematicians. The creation of melody, and of proofs (in mathematics) that the truth of a certain proposition is undecidable, are, he believes, the greatest mysteries.

Robert Walgate

\section{ESA names European candidates for first Spacelab mission}

THE European Space Agency (ESA) has named the four candidates from whom one will be selected to serve, along with one American scientist, as a "payload specialist" on the joint US --European Spacelab mission scheduled for the second half of 1980. The candidates were presented at a press conference on 22 December at ESA's headquarters in Paris. They are Franco Malerba, 31, an Italian electronics engineer and physicist; Ulf Merbold, 36, a West German physicist and staff member of the Max Planck Institut fur Metallforschung in Stuttgart, where he has been researching crystal lattice defects; Claude Nicollier, 33, a Swiss astronomer; and Wubbo Ockels, 31, a Dutch physicist who is doing research at the Nuclear Physics Accelerator Institute in Groningen.

With the exception of Malerba, all are married with one child. Ockels is the only non-flier in the group. Merbold is a glider pilot, Malerba holds a private pilot licence and Nicollier, after working as a professional pilot for Swiss Air, is still in the Swiss Air Force.

After three months of Spacelab familiarisation at European facilities and further evaluation in Houston, one of the four candidates will be eliminated. After next May the other three will continue training until a few months before the flight when one of them will be chosen to be the first European to travel and work in earth orbit. The other two will act as back-up specialists on the ground. On the first ESA/NASA mission lasting one week, the two scientists will be responsible for a payload of 76 experiments in the \& fields of materials science, atmospheric physics, life sciences, solar physics, astronomy, earth observation and space technology.

"We were not looking for a superman or superwoman," said Michel Bignier, Director of the Spacelab programme. $\mathrm{He}$ explained that the scientists would be working in a pressurised "shirt-sleeve" atmosphere. Nonetheless, the evaluation criteria had been particularly severe--equivalent to level II criteria used by NASA to select permanent mission specialists. "Nobody wanted to run the risk of a rejection by NASA," added $\mathrm{Mr}$ Bignier.

By last September, 53 candidates had been preselected from 2,000, including 35 women, who had responded to ESA's announcement of opportunity issued in April. One woman, AnnyChantal Levasseur-regourd of France, was among 12 finalists but failed on the last medical test.

Candidates were screened by four panels of experts covering general assessment and system engineering, scientific, psychological, and medical tests. All the candidates agreed that the psychological testing, carried out at the DFVLR Institute for Flight Medicine in Hamburg, was particularly arduous. Klaus-Martin Goeters, a member of the institute and head of the psychological panel said that tests were aimed at ensuring that those selected could cope with the stress created by the heavy Spacelab workload and the unusual environment. Drawing a typical personality profile, Dr Goeters described the successful candidate as "someone who is highly motivated, with a tendency to be an introvert, preferring small groups to a larger social context, who is unpretentious in habits and life style, thus capable of envisaging certain privations, and is highly mobile: that is a person interested in and looking for new things-with, you might even say, a taste for adventure".

Betty Werther

\section{Sorry, for copyright reasons some images on this page may not be available online}

